\title{
Effect of Triclosan on the Renal Cortex of Adult Male Albino Rats and the Possible Protective Role of Ellagic Acid: Histological and Biochemical Study
}

Zeinab A. Hassan ${ }^{1,2}$, Manal R. Abd El-Haleem ${ }^{1}$ and Ghada N. Mansour ${ }^{3}$

${ }^{1}$ Department of Histology and Cell Biology, Faculty of Medicine, Zagazig University, Egypt

${ }^{2}$ Department of Anatomy, Faculty of Medicine, Tibah University, Madina, Saudi Arabia

${ }^{3}$ Forensic and Toxicology Department, Faculty of Medicine, Zagazig University, Egypt

\begin{abstract}
Background: Triclosan (TCS) is widely used broad spectrum bactericide. Ellagic acid (EA) has radical scavenging properties.

Aim of the work: to assess the structure of the renal cortex after TCS administration and to determine the possible protective role of EA.

Materials and methods: Thirty adult male albino rats were divided into three groups; control group, TCS treated group: TCS was administered $200 \mathrm{mg} / \mathrm{kg}$, once daily for six week, by oral gavages. TCS-EA treated group: received in the same doses of TCS and EA (30 mg/kg) for six weeks. Blood urea nitrogen (BUN), serum creatinine (Sc) and uric acids (UA) were measured. Renal cortex samples were processed for light and electron microscope examination.

Results: Examination of TCS treated group revealed increased glomerular cellularity in some corpuscles. Podocytes showed effacement of the foot processes and focal thickening of the glomerular basement membrane. Some tubules showed marked cellular disorganization. Disoriented basal mitochondria, areas of rarified cytoplasm and electron-dense bodies were noticed. Intense positive caspase-3 reaction was expressed in the tubular cells. TCS-EA showed improvement of morphological organization of renal cortex glomeruli, proximal and distal tubules with moderately expressed caspase-3 in renal tubules Statistical analysis showed significant increase of BUN, SC and BUN in TCS treated group in comparison with the control group. Their levels in TCS-EA treated group showed a significant decrease in comparison with TCS treated group
\end{abstract}

Conclusion: In conclusion, TCS leads to alterations in the histological structure and functions of renal cortex of albino rats and EA supplementation could protect from these changes.

Keywords: Renal cortex; Triclosan; Ellagic acid; Caspase-3

\section{Introduction}

Triclosan (TCS) (2,4,4'-trichloro-2'-hydroxydiphenyl ether) is a member of bisphenols compounds [1]. TCS is abroad spectrum bactericide. It is extensively used in many personal care products including soap, deodorants, hand sanitizer, cosmetics and toothpaste as well as household products such as odour-fighting socks and germresistant sponges [2]. TCS has antiseptic activity through disrupting bacterial membrane activities and inhibits fatty acid synthase involved in lipid biosynthesis [3].

The widespread TCS use, make the potential to its exposure for the general population through ingestion of food and drinking water contaminated with it or dermal contact with products containing it $[3,4]$. TCS was detected in the blood [5], breast milk [6] and urine [7]. It is bioaccumulated and concentrated in the fatty tissues of worldwide people [8]. It is also has been found in rivers, streams and in sewage sludge applied to agriculture [9]. Urinary excretion was found to be a major route of elimination [3].

TCS is an endocrine disruptor; previous studies have shown that TCS disrupts thyroid hormone action [10]. TCS also has estrogenic and androgenic hormone properties. TCS exposure could potentially contribute to the development of breast cancer [11].

Flavonoids, which are polyphenolic antioxidants, occur naturally in vegetables and fruits. Ellagic acid (2,3,7,8-Tetrahydroxychromeno [5,4,3cde]chromene-5,10-dione) is also a naturally occurring phenolic constituent in certain fruits and nuts [12]. EA is mostly abundant in berries, walnuts, pecans, pomegranate, cranberries and other plant foods in the forms of hydrolysable tannins called ellagitannins [13]. Ellagic acid (EA) as phytochemical has received particular attention because of its wide array of biological properties, such as radical scavenging, antiviral and antibacterial properties [14].

Programmed cell death occurs following the induction of an intracellular genetically regulated cell death program. A number of physiological and pathological stimuli including lack of nutrients, activation of cell surface death receptors, chemicals, ionizing radiation and direct physical injury can activate the apoptosis [15].

Caspases are a group of enzymes that are involved in the regulation of apoptosis resulting in the classical apoptotic features. Caspase 3 activation occurs in response to variety of apoptotic inducers which activate endonuclease and induce DNA fragmentation [16].

Despite the extensive use of TCS, few studies have investigated the

*Corresponding author: Zeinab A. Hassan, Department of Histology and Cell Biology, Faculty of Medicine, Zagazig University, Zagazig, Egypt, Faculty of Medicine, Tibah University, Madinah, Saudi Arabia, Tel: 00201223467226; E-mail: zeinabrehim66@gmail.com

Received September 09, 2014; Accepted October 16, 2014; Published October 18, 2014

Citation: Hassan ZA, Abd El-Haleem MR, Mansour GN (2014) Effect of Triclosan on the Renal Cortex of Adult Male Albino Rats and the Possible Protective Role of Ellagic Acid: Histological and Biochemical Study. J Cytol Histol 5: 285. doi:10.4172/2157-7099.1000285

Copyright: (C) 2014 Hassan ZA, et al. This is an open-access article distributed under the terms of the Creative Commons Attribution License, which permits unrestricted use, distribution, and reproduction in any medium, provided the original author and source are credited. 
toxicological effect of TCS. So, this study aimed to assess the structure of the renal cortex after TCS administration and to evaluate the possible protective role of EA.

\section{Material and Methods}

\section{Material}

\section{Chemicals:}

- Triclosan (Sigma Aldrich Company, Methyl TCS, $\mathrm{Cl}_{3} \mathrm{H}_{9} \mathrm{Cl}_{3} \mathrm{O}_{2}$ CAS Number: 4640-01-1).

- Ellagic acid (Sigma Aldrich Company, E2250, $\geq 95 \%$ (HPLC), powder, from tree bark, CAS-No. : 476-66-4)

\section{Kits:}

- Biomerieux France kits for estimation of blood urea nitrogen (BUN) and serum creatinine (SC) and uric acid (UA).

- Caspase-3: anti-Caspase 3 (CPP32) Ab-4, 4, rabbit polyclonal antibody (CAT. \# RB-1197-P0, ready to use, Thermo Scientific ${ }^{\text {tw }}$ Lab vision.

Experimental animals: Thirty adult male albino rats, with an average weight of $200 \mathrm{~g}$, were used in this study. Rats were housed in wire mesh cages and were fed with pelleted standard chow diet in addition to tap water. Animals were kept for 7 days before beginning the experiment for acclimatization. The experimental protocols were approved by the Ethical Committee of Zagazig University.

\section{Methods}

Experimental design: Animals were randomly divided into the following groups; Group I (control group): This group included 18 rats that was further equally subdivided into 3 equal subgroups; Group 1A (negative control group): were gavaged with $1 \mathrm{ml}$ of distilled water once daily for 6 weeks. Group 1B (corn oil positive control group): were orally gavaged $1 \mathrm{ml}$ of corn oil (a vehicle) once daily for six weeks. Group 1C (EA positive control group): were gavaged with EA alone. Group II: (TCS treated group): included 6 rats that received TCS alone. The dose was selected on the basis of the oral LD50 $(5000 \mathrm{mg} / \mathrm{kg}$, in rats) [17]. Group III (TCS-EA treated group): included 6 rats that received the same dose of TCS, 1 hour subsequent to administration of EA.

Rats of groups II and III received TCS in a dose of $200 \mathrm{mg} / \mathrm{kg}$ (suspended in $1 \mathrm{ml}$ of corn oil) by oral gavages once daily for six weeks [15]. Rats of groups IC and III received EA at a dose $30 \mathrm{mg} / \mathrm{kg}$ (dissolved in corn oil) by oral gavages, once daily for six weeks [18].

At the end of experiment, the rats were anesthetized with $50 \mathrm{mg} /$ kg.bw sodium pentobarbital intraperitoneally [19]. Blood samples were obtained directly from the heart by cardiac puncture. Blood samples were collected into tubes containing ethylenediamine-tetraacetic acid (EDTA) and centrifuged at $3000 \mathrm{~g}$ for $10 \mathrm{~min}$. Plasma was separated and then stored at $20^{\circ} \mathrm{C}$ until analyzed. Then intra-cardiac perfusion was done by $2 \%$ glutaraldehyde for fixation.

Histological study: The cortex of both kidneys of each animal was dissected, excised and cut into smaller pieces and processed for light $\left(1 \mathrm{~cm}^{3}\right)$ and electron microscope $\left(1 \mathrm{~mm}^{3}\right)$ study. To prepare paraffin blocks, specimens were immediately placed in $10 \%$ buffered formalin. After $10 \mathrm{~min}$, when the tissue was hardened to avoid soft tissue dissipation, specimens were fixed in $10 \%$ buffered formalin for $24 \mathrm{~h}$ and processed to prepare $5 \mu \mathrm{m}$ sections stained with haematoxylin and eosin, Masson's trichrome and PAS stains [20].
The immunohistochemical staining for localization of the caspase -3 was carried out by means of the avidin biotin- peroxidase complex method following the manufacturer's instructions (Dako Company, Wiesentheid/Bavaria, Germany, Biotin Blocking System, Code X0590). Paraffin sections of $4 \mu \mathrm{m}$ were deparaffinized in xylene and rehydrated in a descending series of ethanol. The specimens were subjected to antigen retrieval in a citrate buffered solution $(\mathrm{pH} \mathrm{6.0)}$ for 10 minutes using a microwave. Endogenous peroxidase was eliminated by incubation in $10 \% \mathrm{H}_{2} \mathrm{O}_{2}$ in phosphate-buffered saline (PBS), $\mathrm{pH} 7.4$ for 10 minutes. After washing, the specimens were blocked in ready-use normal goat serum for 20 minutes at room temperature. Then, the sections were incubated with the specific anti-Caspase 3 primary antibody at room temperature for 30 minutes. Dilutions were done with antibody diluent (TA-125-UD; Lab Vision). Peroxidase activity was demonstrated using an AEC (3-amino-9-ethyl carbazole) substrate kit (TA-004-HAC; Lab Vision). The sections were rinsed in PBS. It was applied overnight (1:200) in a humidified chamber at $4^{\circ} \mathrm{C}$ then washed in PBS twice. The secondary antibody was anti-rabbit antibody universal kit (code no. Ko773, lot). Sections were covered with biotinylated secondary antibody for 30 minutes and then washed in PBS. Then by peroxidaselabeled avidin/ biotin solution reaction (Novo Stain Super ABC Kit, Novocastra, Newcastleupon -Tyne, UK) for 45 minutes. then washed in PBS. Finally, freshly prepared diaminobenzidine (Sigma, St. Louis, MO) was added for 4 minutes. A chromogen, washed with distilled water followed by Mayer's haematoxylin as a counter stain. The sections were washed, dehydrated mounted and examined. For the negative control, the same steps were followed, but the primary antibody was replaced by PBS [21]. Brown caspase 3 positive immunoreaction is predominantly cytoplasmic with some nuclear staining [22].

Specimens for electron microscope were immediately fixed in $2.5 \%$ phosphate-buffered glutaraldehyde ( $\mathrm{pH}$ 7.4). Renal cortex specimens were immediately fixed in $2.5 \%$ glutaraldehyde in $0.1 \mathrm{M}$ cacodylate buffer at $\mathrm{pH} 7.4$ for $24 \mathrm{~h}$ at $4^{\circ} \mathrm{C}$. Then the specimens were washed with the buffer, post fixed in $1 \%$ osmium tetroxide in distilled water for $2 \mathrm{~h}$ at $4^{\circ} \mathrm{C}$. They were dehydrated with ascending grades of ethanol and then put in propylene oxide to prepare Epon-Aralditresin blocks. Ultrathin sections were stained with uranyl acetate and lead citrate [23] and examined and photographed using a JEOL JEM 1010 electron microscope (JEOL Ltd, Tokyo, Japan) in the Electron Microscope Research Laboratory of the Histology and Cell Biology Department, Faculty of Medicine, Zagazig University (Egypt).

Morphometric study: Quantitative morphometric measurements were obtained using a Leica Qwin 500 image analyzer computer system (Leica, Hessen, Germany): Faculty of Medicine, Zagazig University, Egypt. The area percentage (area \%) of positive immune reaction for caspace- 3 was measured using the interactive measure menu. The area percentage and standard measuring frame of a standard area equal to $118476.6 \mu \mathrm{m}^{2}$ were chosen from the parameters measuring 10 readings from five sections from each rat of the randomly chosen five rats in each group. In each randomly chosen field, the section of the renal cortex was enclosed inside the standard measuring frame; the areas where brown positive immune reaction for caspace- 3 were measured. The whole data was subjected to statistical analysis.

Biochemical study: Assessment of kidney function tests had been carried out using kit of Biomerieux France.

Blood urea nitrogen $(\mathrm{BUN})(\mathrm{mg} / \mathrm{dL})$ and serum creatinine $(\mathrm{SC})$ $(\mathbf{m g} / \mathbf{d L})$ : They were done according to the pamphlet of Biomerieux France kit by enzymatic colorimetric method. 
Citation: Hassan ZA, Abd El-Haleem MR, Mansour GN (2014) Effect of Triclosan on the Renal Cortex of Adult Male Albino Rats and the Possible Protective Role of Ellagic Acid: Histological and Biochemical Study. J Cytol Histol 5: 285. doi:10.4172/2157-7099.1000285

Serum uric acid (mmol/L): Serum uric acid was measured according to the pamphlet of Biomerieux France kit, by a carbonate phosphotungstate method

Statistical analysis: Data obtained from hormonal assay and morphometry were expressed as mean \pm SD. They were fed into the computer using statistical package for the social sciences (SPSS, version 20; IBM, Armonk, New York, USA) software package. Statistical analysis was carried out using one-way analysis of variance and the posthoc test (Scheffe) for pairwise comparison. The level of significance was set at $\mathrm{P}$ value less than 0.05 .

\section{Results}

\section{Histological results}

Light microscope results: Histological examination of all control subgroups IA, IB and IC showed nearly similar structure. Figures for subgroup IA were used to differentiate with other groups. Examination of $\mathrm{H} \& \mathrm{E}$ stained sections of the control adult male albino rat renal cortex showed normal renal structure. Each renal corpuscle was formed of a glomerular tuft of capillaries surrounded by Bowman's capsule. Proximal and distal convoluted tubules cells showed acidoplic cytoplasm and vesicular nuclei (Plate 1A). Examination of TCS treated group revealed increased glomerular cellularity with obliteration of the Bowman's space in some renal corpuscles. Other glomeruli appeared destructed with dark stained nuclei. Some tubules showed desquamation of tubular epithelial cells while others show marked cellular disorganization. Intracellular vacuoles and luminal casts were

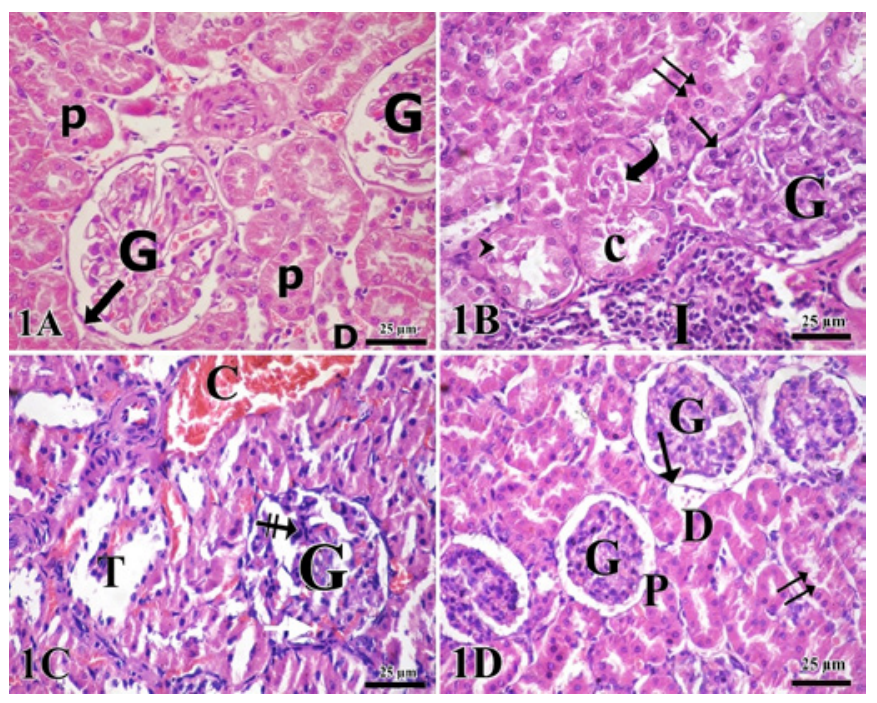

Plate 1: A: Control group renal cortex showing renal corpuscles. Glomeruli (G) formed of capillary tufts are surrounded by Bowman's capsules (arrow). Note acidophilia of proximal $(P)$ and distal $(D)$ convoluted tubules cells with vesicular nuclei. B, C: Triclosan treated group renal cortex showing glomerulus $(G)$ with increased cellularity with obliteration of the Bowman's space (arrow). Some tubules show desquamation of tubular epithelial cells (curved arrow) while others show marked cellular disorganization (double arrows). Intracellular vacuoles (arrowhead) and casts (c) are observed in some tubules. Many inflammatory cells $(\mathrm{I})$ are noticed. Other glomerulus $(\mathrm{G})$ appears destructed with dark stained nuclei (crossed arrow) and congested capillaries (white arrow). Dilated tubules $(\mathrm{T})$ with flattened epithelium are detected. Congested blood vessels (C) are also seen. D: Triclosan-ellagic acid group renal cortex showing glomeruli $(G)$ with their capillary tufts, surrounded by Bowman's capsules (arrow). Proximal (P) and distal convoluted tubules cells (D) haveacidophilic cytoplasm and vesicular nuclei Few distorted tubules (double arrow) could be seen. (scale bar $25 \mu \mathrm{m}, \mathrm{H} \& \mathrm{E}$ stain).

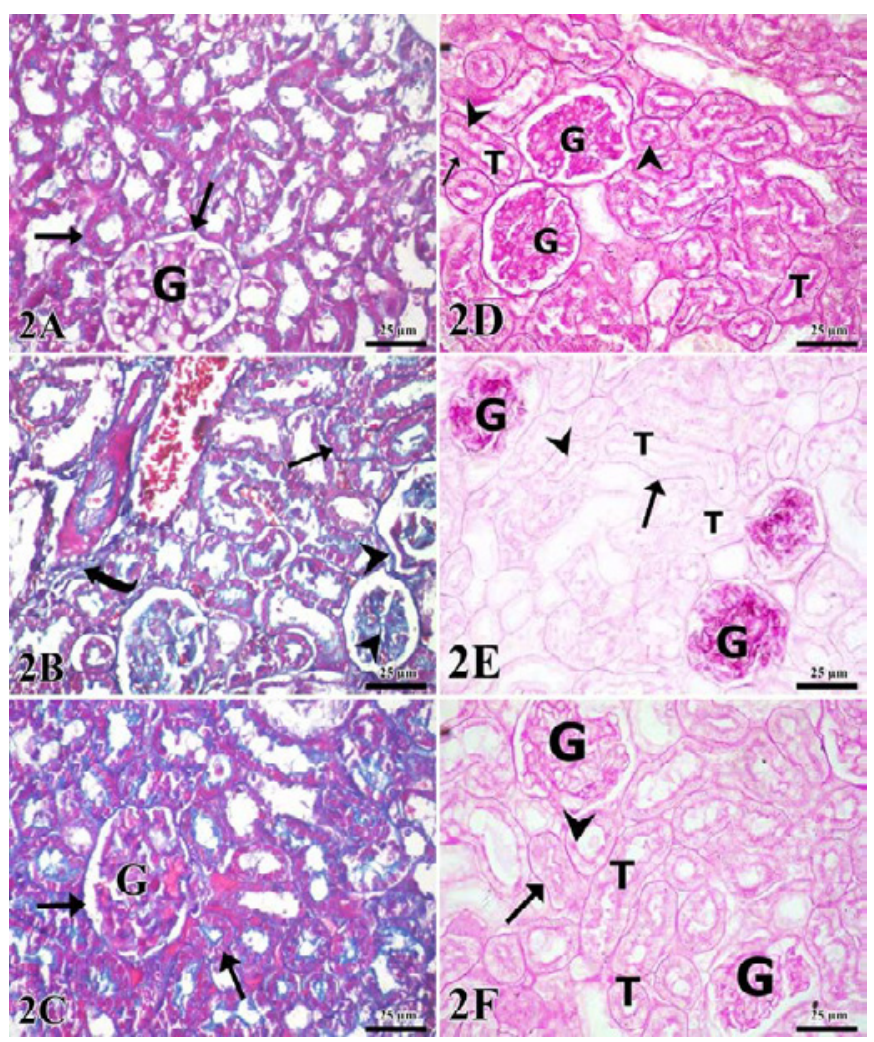

Plate 2: A: Control group renal cortex showing thin blue collagen fibers (arrow) around the renal corpuscle (G) and tubules. B: Triclosan treated group showing excess blue-stained collagen fibers around tubules (arrow), around and within glomeruli (arrowhead). Foci of interstitial fibrosis (curved arrow) are also noticed. C: Triclosan-ellagic acid treated group showing blue collagen fibers (arrow) around the renal corpuscle and tubules. D: Control group showing intense PAS +ve reaction reaction in the basal lamina (arrow), luminal brush border (arrowheads) of the renal tubules $(T)$ and renal glomeruli (G). E: Triclosan treated group showing strong PAS + ve reaction in the renal glomeruli $(G)$ while renal tubules $(T)$ show moderate reaction in basal lamina (arrow), luminal brush (arrow head) border. .F: Triclosan-ellagic acid treated group showing moderate PAS +ve reaction in the basal lamina (arrow), luminal brush (arrow head) border of the renal tubules $(T)$ and glomeruli $(G)$. (scale bar $25 \mu \mathrm{m}, \mathrm{A}, \mathrm{B}, \mathrm{C}$; Masson's trichrome stain \& D, E, F; PAS stain).

observed in other tubules. Dilated tubules with flattened epithelium were detected. Many inflammatory cells and congested blood vessels were also seen. (Plate 1B and 1C). Examination of TCS-EA showed improvement of morphological organization of renal cortex, glomeruli of renal corpuscles appeared with their capillary tufts surrounded by Bowman's capsules. Proximal and distal convoluted tubules cells appeared with acidophilic cytoplasm. Most of their nuclei were vesicular. However, few distorted tubules were also detected (Plate 1D).

Examination of Masson's trichrome stained sections of control group renal cortex group showing thin blue collagen fibers around renal corpuscles and tubules (Plate 2A). On the other hand, examination of TCS treated group revealed excess blue-stained collagen fibers around the tubules, around and within the glomeruli. Foci of interstitial fibrosis were also noticed (Plate 2B). In TCS-EA treated group, blue collagen fibers were observed around the renal corpuscle and tubules (Plate 2C).

Examination of PAS stained sections of control group revealed positive PAS reaction in the basal lamina, luminal brush border of the renal tubules and renal glomeruli (Plate 2D). On the other hand, TCS treated group revealed intense positive PAS reaction in the renal 
Citation: Hassan ZA, Abd El-Haleem MR, Mansour GN (2014) Effect of Triclosan on the Renal Cortex of Adult Male Albino Rats and the Possible Protective Role of Ellagic Acid: Histological and Biochemical Study. J Cytol Histol 5: 285. doi:10.4172/2157-7099.1000285

glomeruli while renal tubules show moderate reaction (Plate 2E). In TCS EA treated group, moderate positive PAS reaction in the basal lamina and luminal brush border of renal tubules and glomeruli were detected (Plate 2F).

Immunohistochemical examination of control group revealed minimal positive cytoplasmic staining for caspase- 3 in cells of proximal and distal tubular cells (Plate 3A). However, TCS treated group showed
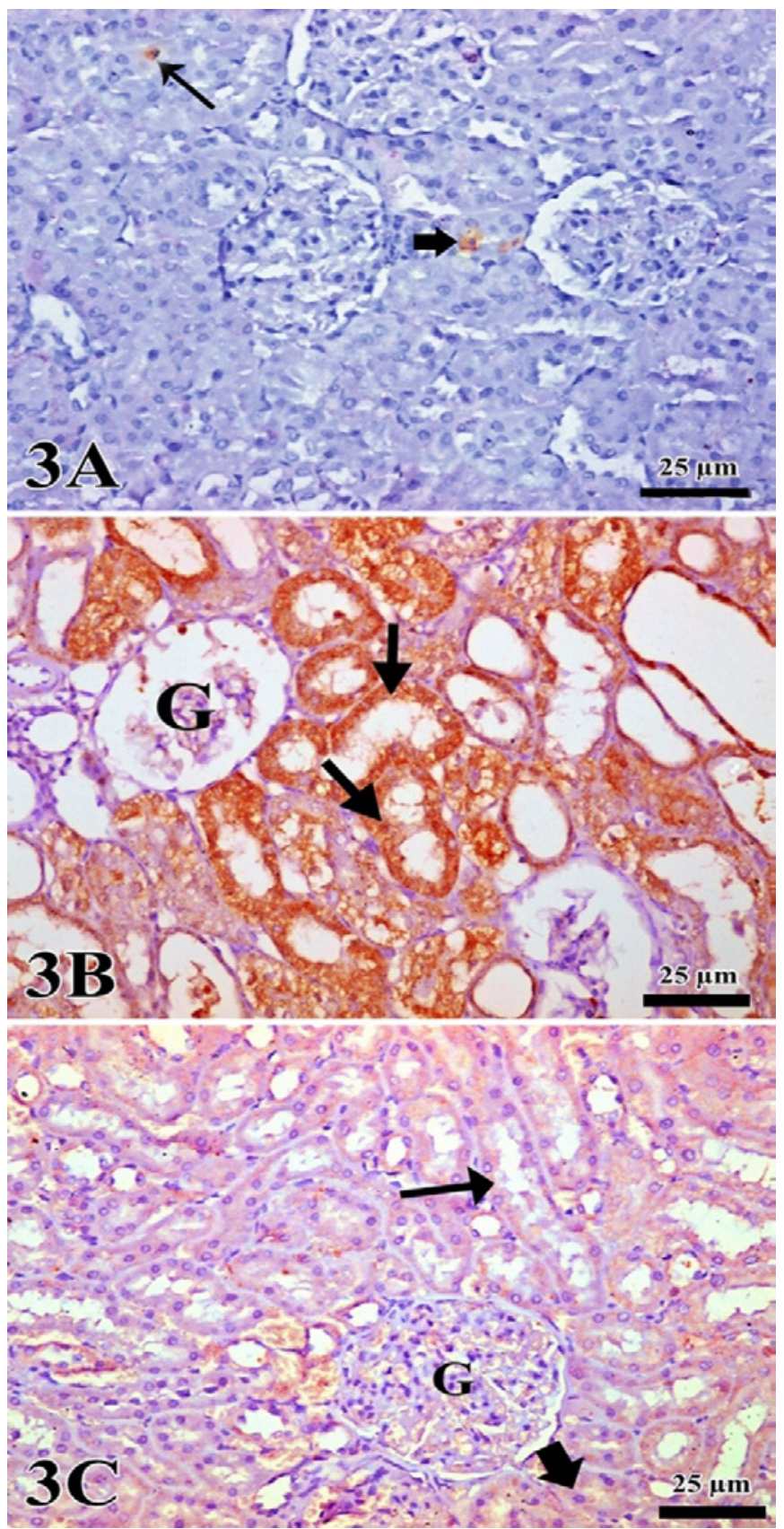

Plate 3: A: Control group shows minmal caspase-3 positive reaction in cells of proximal (thick arrow) and distal (thin arrow) tubular cells B: Triclosan treated group shows intense caspase- 3 positive reaction (arrow) expressed in the cytoplasm and nuclei of the tubular cells and moderately expressed reaction in glomeruli ( $G$ ) C: Triclosan-ellagic acid treated group shows moderately expressed caspase-3 reaction of glomeruli $(G)$, proximal (thick arrow) and distal (thin arrow) tubules. (scale bar $25 \mu \mathrm{m}$, caspase-3 immunostain)

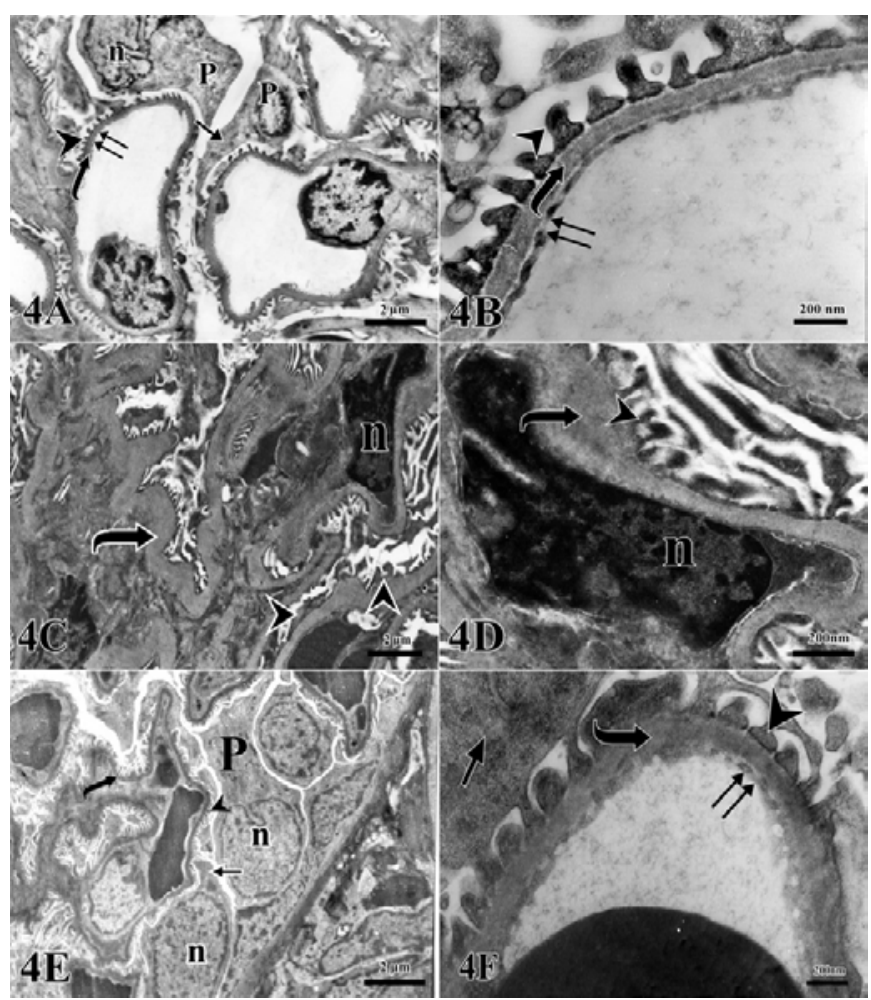

Plate 4: A, B: Control group showing podocytes $(P)$ and processes. Observe irregular euchromatic nucleus of podocyte $(n)$ and the fenestrated endothelium of the capillary (double arrows). Primary process (arrow), interdigitating secondary process (arrow head) is noticed. GBM (curved arrow) is formed of a central electron dense lamina densa and lamina rarae on either side. C, D: Triclosan treated group showing podocytes with electron dense nuclei ( $n$ ) with effacement of the foot processes (arrow head) and focal thickening of the glomerular basement membranes (curved arrow). E, F: Triclosan-ellagic acid treated group showing podocytes $(P)$ with irregular electron lucent nuclei (n). Their primary processes (arrow), secondary processes (arrow heads) and uniform thickness of GBM (curved arrow) are also detected. Fenestrated blood capillary (double arrows) could also noticed. (scale bar, A, C, E: $2 \mu \mathrm{m} \& \mathrm{~B}$, D, F: $200 \mathrm{~nm}$ )

intense caspase- 3 positive reaction expressed in the cytoplasm and nuclei of the tubular cells and moderate reaction were also noticed in glomeruli (Plate 3B). In addition, TCS-EA treated group showed moderately expressed caspase- 3 in glomeruli, proximal and distal tubules (Plate 3C).

Electron microscope results: Ultrastructural examination of the glomeruli of control group kidney showed podocytes with irregular euchromatic nuclei, primary processes and interdigitating secondary processes. The glomerular basement membranes (GBM) were formed of central electron dense lamina densa and lamina rurae on either side. Fenestrated blood capillaries were also detected (Plate 4A and 4B). In TCS treated group, many podocytes showed electron dense nuclei with effacement of the foot processes and focal thickening of the GBM (Plate 4C and 4D). In TCS-EA treated group, podocytes appeared with irregular electron lucent nuclei. Relatively normal arrangement of secondary foot processes and regular thickening of the GBM with restoration of its trilamellar structure are seen. Fenestrated blood capillaries were also detected (Plate $4 \mathrm{E}$ and $4 \mathrm{~F}$ ).

Examination of proximal convoluted tubules (PCTs) of control group showed epithelial cells lining proximal convoluted tubules with 
Citation: Hassan ZA, Abd El-Haleem MR, Mansour GN (2014) Effect of Triclosan on the Renal Cortex of Adult Male Albino Rats and the Possible Protective Role of Ellagic Acid: Histological and Biochemical Study. J Cytol Histol 5: 285. doi:10.4172/2157-7099.1000285

long apical microvilli and large euchromatic nuclei, some of them had prominent nucleoli. Many elongated basal mitochondria were seen inbetween extensive basal infoldings. All cells were rest on basal lamina (Plate 5A and 5B). In TCS treated group, cells showed disoriented basal mitochondria with very few basal infoldings. Multiple cytoplasmic vacuoles, areas of rarified cytoplasm and electron-dense bodies were noticed. Nuclei with clumps of heterochromatin and apoptotic nuclei were are apically displaced. Casts with different electron density were found at the tubular lumen. Apical long microvilli were preserved on some cells while others show sparse short microvilli. Irregular basal laminas were also noticed (Plate 5C and 5D). TCS-EA group showed many PCT cells with numerous apical long microvilli, euchromatic nuclei, many mitochondria, electron-dense bodies and apical vacuoles were detected in their cytolasm. Cells were rest on regular basal lamina (Plate 5E and 5F).

Examination of distal convoluted tubules (DCTs) of control group revealed epithelial cells with oval nuclei and few short apical microvilli. Many elongated basal mitochondria were seen in-between

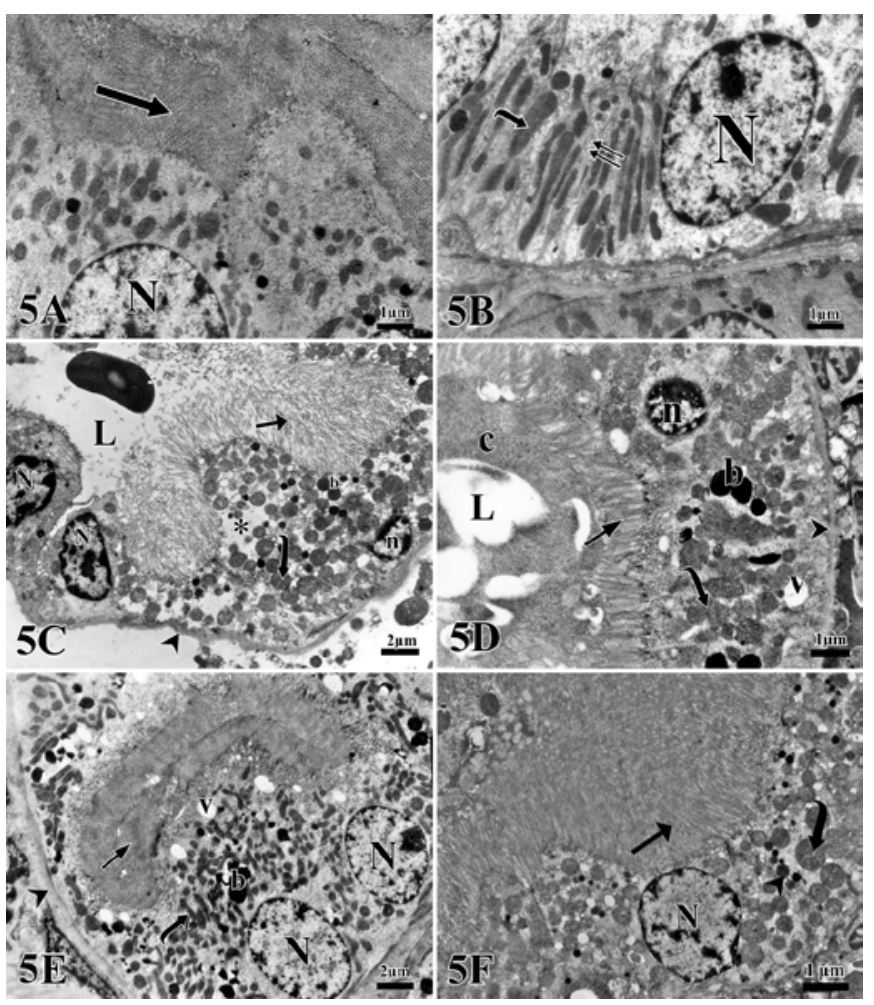

Plate 5: Electron micrographs of a proximal convoluted tubule (PCT) cells. A, B: Control group showing a proximal convoluted tubule epithelial cells lining with large euchromatic nuclei $(\mathrm{N})$, prominent nucleolus and long apical microvilli (arrow). Many elongated basal mitochondria (curved arrow) are seen in-between extensive basal infoldings (double arrows) are also noticed. All cells are rest on basal lamina. C,D: Triclosan treated group showing a disoriented basal mitochondrial (curved arrow). Multiple cytoplasmic vacuoles (v), electron-dense bodies (b) and areas of rarified cytoplasm $\left(^{*}\right)$ are noticed. Apically displaced nuclei with clumps of heterochromatin $(N)$ and apoptotic nuclei (n) are detected. Casts (c) with different electron density are found at the tubular lumen (L). Apical long microvilli (arrow) are preserved on some cells, while others show sparse short microvilli (double arrows). Irregular basa lamina (arrow head) could be seen. E,F: Triclosan-ellagic acid treated group showing euchromatic nuclei $(\mathrm{N})$ and mitochondria (curved arrow), electrondense bodies (b) and apical vacuoles (v). Numerous apical long microvilli (arrow) are also noticed. Regular basal lamina is also noticed (arrow head). (Images scale bar, A,B,D,F; $1 \mu \mathrm{m} \& \mathrm{C}, \mathrm{E} ; 2 \mu \mathrm{m}$ ).

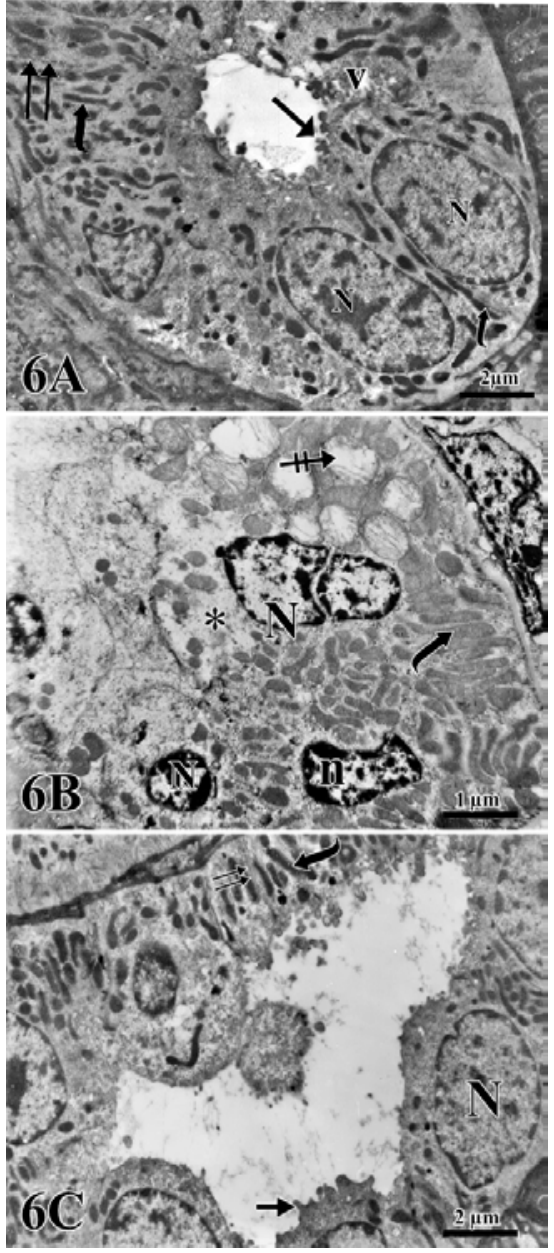

Plate 6: Electron micrographs of a distal convoluted tubule (DCT). A: Control group showing lining cells with oval nuclei $(\mathrm{N})$ and few short apical microvilli (arrow). Many elongated basal mitochondria (curved arrow) are seen inbetween basal infoldings (double arrows). Small vacuoles (v) were found in the cytoplasm. B: Triclosan treated group showing cells with areas of rarified cytoplasm (asterisk), many mitochondria (curved arrow), and some of them have swollen disrupted cristae (crossed arrow head). Some cells show nuclei with multiple peripheral patches of heterochromatin $(\mathrm{N})$ while others have deeply indented nuclear envelope (n). Apical displacements of all nuclei are also noticed. C: Triclosan-ellagic acid treated group showing many euchromatic nuclei $(\mathrm{N})$, few short apical microvilli (arrow), and elongated mitochondria (curved arrow) in-between basal infoldings (double arrow). scale bar $2 \mu \mathrm{m} \& B,: 1 \mu \mathrm{m})$

( A, C :

basal infoldings. Small vacuoles were found in the cytoplasm (Plate 6A and 6B). In TCS treated group, cells showed areas rarified cytoplasm, many mitochondria; some of them appeared swollen with disrupted cristae. Some cells showed nuclei with multiple peripheral patches of heterochromatin while others showed deeply indented nuclear envelope. Nuclear displacement were also noticed (Plate 6C and 6D). In TCS-EA group, many cells had euchromatic nuclei, few short apical microvilli, and mitochondria in-between basal infoldings (Plate 6E and 6F).

Morphometrical Results: The mean area percentage of caspase-3 expression for all groups is presented in (Table 2): there was a significant increase $(\mathrm{P}<0.05)$ in caspase- 3 expression in TCS treated group (II) compared with control group (1A). There was a significant decrease $(\mathrm{P}<0.05)$ in caspase- 3 expression in TCS-EA treated group (III) compared with TCS treated group (II) 


\begin{tabular}{|l|c|c|}
\hline Group & blood urea nitrogen (BUN) mg/dl & serum creatinine (SC) mg/dl \\
\hline $\begin{array}{l}\text { Group IA } \\
\text { (negative control group) }\end{array}$ & $25.76 \pm 1.02$ & $1.22 \pm 0.23$ \\
\hline $\begin{array}{l}\text { Group IB } \\
\text { (Corn oil- positive control group) }\end{array}$ & $26.83 \pm 1.14^{\mathrm{n}}$ & $1.25 \pm 0.12^{\mathrm{n}}$ \\
\hline $\begin{array}{l}\text { Group IC } \\
\text { (EA -positive control group) }\end{array}$ & $27.17 \pm 2.10^{\mathrm{n}}$ & $0.97 \pm 0.043^{\mathrm{n}}$ \\
\hline $\begin{array}{l}\text { Group II } \\
\text { TCS treated group }\end{array}$ & $60.58 \pm 2.18^{\mathrm{a}}$ & $2.86 \pm 0.19^{\mathrm{a}}$ \\
\hline $\begin{array}{l}\text { Group III } \\
\text { TCS-EA treated group }\end{array}$ & $29.35 \pm 2.76^{\mathrm{b}}$ & $1.481 \pm 0.22^{\mathrm{n}}$ \\
\hline
\end{tabular}

${ }^{n}$ non significant difference with the group IA

a significant difference with the group IA

${ }^{\mathrm{b}}$ significant difference with the group II

Table 1: Mean values of blood urea nitrogen $(\mathrm{mg} / \mathrm{dl})$, serum creatinine $(\mathrm{mg} / \mathrm{dl})$, uric acid $(\mathrm{mmol} / \mathrm{L})$ in subgroup IA, IB, and IC of control group, group II, and group III.

\begin{tabular}{|l|c|c|c|c|}
\hline \multirow{2}{*}{} & & \multicolumn{2}{|c|}{ Mean \pm SD } \\
\cline { 2 - 5 } area \% of caspase-3 positive immune-expression & Group IA & Group IB & Group IC & Group II \\
\hline
\end{tabular}

${ }^{n}$ non significant difference with the group IA

a significant difference with the group IA

${ }^{b}$ significant difference with the group II

Table 2: Showing the mean area percentage and optical density of caspase-3 positive immune-expression, in all studied groups.

\section{Biochemical results}

The mean values of blood urea nitrogen $(\mathrm{mg} / \mathrm{dl})$, serum creatinine $(\mathrm{mg} / \mathrm{dl})$, uric acid $(\mathrm{mmol} / \mathrm{L})$ for all groups is presented in Table 1. There was no significant difference between the biochemical results of group IA, group I B, and group IC. So, the biochemical results of group IA were chosen to express the results of control group and compare with the rest of groups. There was significant increase in the levels of BUN, SC and BUN in group TCS treated group in comparison with the control group. On the other hand, the level of BUN, SC and UA in TCS-EA treated group showed a significant decrease in comparison with TCS treated group.

\section{Discussion}

TCS is as a chlorinated aromatic polychloro-phenoxy phenol compound that has functional groups representative of both ether and phenols [24]. Biodegradation and photolytic degradation diminish the availability of TCS. However, TCS by-products such as methyl-triclosan and other chlorinated phenols may be more resistant to degradation and have higher toxicity than the parent compound [10]. Also, TCS irradiation by sunlight can degrade into a form of dioxin, a class of chemicals linked to a broad range of toxicities cispla $[25,26]$.

Examination of TCS treated group revealed increased glomerular cellularity with obliteration of the Bowman's space in some glomeruli while others appeared destructed with dark stained nuclei. Many podocytes had electron dense nuclei with effacement of the foot processes and focal thickening of the glomerular basement membranes. The mechanism of TCS induced cytotoxicity could by explained by Lock and reed and Mathur and D'Cruz [27,28]. Lock and reed [27] stated that TCS metabolism have been shown to undergo via a minor pathway of glutathione conjugation. These conjugates formed accumulate within the kidney where they undergo activation to a chemically reactive species which can introduce an acyl group into proteins leading to renal cell necrosis and compensatory cell regeneration. Mathur and D'Cruz [28] stated exposure to TCS caused an imbalance in prooxidant/ antioxidant levels and thereby induces the generation of ROS. Tipping [29] postulated that podocytes are generally regarded as targets of reactive ROS by stimulating podocyte production of the proinflammatory cytokine GM-CSF that induced apoptosis in podocytes and directly injure the glomerular basement membrane. Binelli et al. [30] added that TCS acts as a DNA adduct and exerts genotoxic effects leading to apoptotic damage.

In TCS treated group, some tubules showed desquamation of tubular epithelial cells while others show marked cellular disorganization. Dilated tubules with flattened epithelium were detected. Many inflammatory cells and congested blood vessels were also noticed. Tubular cells had many multiple cytoplasmic vacuoles, areas of rarified cytoplasm electron-dense bodies and luminal casts were detected. These findings were in accordance with the works performed by Dann and Hontela [10] who reported that TCS were primarily changes in the kidneys evidenced by inflammation and tubular degeneration. Moreover, previous reports linked the chronic TCS toxicity with the occurrence of focal interstitial nephritis, fibrosis, tubular dilatation and eosinophilic casts in the tubulatr lumina [31]. Barlas and Aydoğan [32] stated that phenol induced enlargement of intertubular area with hemorrhage in rats. Tootian et al. [33] attributed that phenol inducing tubular degeneration to vascular stasis in the kidney. The degenerative alterations may be due to its ability to impair epithelial cell membrane integrity. U.S Food and Drug Administration [34] reported that TCS induced renal changes by ROS damaging of variety of transport proteins including $\mathrm{Na} / \mathrm{K}$ ATPase [35]. Reduced $\mathrm{Na}+\mathrm{K}+$-ATPase activity in the proximal tubular epithelial cells resulted in intracytoplasmic vacuolation, disruption of the arrangement and swelling of the mitochondria and large number of lysosomes [36]. Previous studies reported that sloughing of the nonviable cells into the tubular lumen induced formation of casts which cause luminal obstruction leading to decrease in glomerular filtration [37].

In TCS treated group, disorientation of basal mitochondria with very few basal infoldings were detected in renal tubule cells. Also, nuclei with clumps of heterochromatin and apoptotic nuclei were also detected. These results came in agreement with Zucherbraun et al. [38] who suggested that TCS induced tubular cell death by apoptosis. Also, Newton et al. [1] proved that TCS can impair fluidity of the inner mitochondrial membrane resulting in mitochondrial dysfunction. Tootian et al. [33] stated that inefficiency of renal function and structure 
is attributed to mitochondrial destruction. Previously, Kaneda et al. [39] reported that mitochondrial dysfunction reduces active transport of renal tubules which impairs reabsorption capacity of the tubules that may progress to cell death.

TCS treated group showed excess collagen fibers around the tubules, around and within the glomeruli. These results were supported by Efstratiadis et al. [40] who stated that progressive loss of renal function is associated with development of tubulointerstitial renal fibrosis with destruction of renal tubules and interstitial capillaries and accumulation of extracellular proteins. Pozdzik et al. [41] explained that by epithelial to mesenchymal transition (EMT); a process in which of tubular epithelial cells are transformed to mesenchymal fibroblasts migrating to adjacent interstitial parenchyma constitutes main mechanism of renal fibrosis along with local and circulating cells.

TCS administration results in an apparent increase PAS reaction in the renal glomeruli and moderate reaction in renal tubules. Thickened GBM with distorted foot processes of podocytes was noticed. Rateb and Abdel-Hafez [42] attributed this thickening may develop to compensate for the increased glomerular permeability and proteinuria. Oh et al. [43] demonstrated that oxidative stress induced deleterious structural changes, including loss of the brush border membrane, deposition of PAS positive materials, and cast formation.

Examination of TCS-EA group revealed improvement of morphological organization of renal cortex with regular arrangement of secondary foot processes and regular thickening of the GBM with restoration of its trilamellar structure. Cells of proximal and distal convoluted tubules cells appeared nearly normal however few distorted tubules were also detected. These results are in agreement with ALkharusi et al. [18] who proved that EA ameliorate oxidative stress toxicity and decreased the tubular necrosis and apoptotic cells of the renal cortex in rats treated with EA. Ateşşahin et al. [12] reported that EA protected the kidney from tubular degeneration, desquamation and tubular dilatation. Chirino and Pedraza-Chaverri [44] postulated that introduction of an exogenous antioxidant is thought to help the endogenous antioxidant system in scavenging the ROS produced during an imbalance in redox status. In view of the fact that TCS treatment results in decreasing in kidney glutathione [12], EA increased the activity of three antioxidant enzymes superoxide dismutase, glutathione peroxidase and catalase which help in free radical attack [45]. Also, Han et al. [46] reported that EA exhibited antifibrosis effect and increase of free radical scavenging activity and inhibited lipid peroxide production. EA inhibits cytokine-induced ROS, inflammation, and expression of adhesion molecules [47]. Moreover, recent studies have confirmed that EA reducing apoptosis through scavenging ROS [48].

Immunohistochemical examination of TCS treated group showed was a significant increase of caspase- 3 expression in TCS treated group in the cytoplasm and nuclei of tubular cells comparing with control group. On the other hand, there was a significant decrease of caspase-3 expression in TCS-EA treated group in cells of proximal and distal tubules comparing to TCS treated group. These changes of cleaved caspase- 3 due to activation of apoptosis pathways are in accordance with Newton et al. [1] who stated that mitochondrial depolarization induced by TCS is an early event in the promotion of apoptosis. Loro et al. [15] reported that TCS can induce apoptosis by increased levels of ROS [49]. This can subsequently activate extrinsic (Fas and FasL) and intrinsic (mitochondrial) apoptotic pathways. Intrinsic apoptosis pathway is regulated by pro-survival proteins and proapoptotic protein. Dysregulation of these proteins results in the release of cytochrome C (pro-apoptotic factor) from outer mitochondrial membrane to cytoplasm resulting in activation of caspase-9. Activated caspase-9 triggers the effector caspase-3 [50]. Kuhla et al. [51] stated that extrinsic apoptotic pathway by binding of death receptors which, bind to caspase- 8 and activates effector caspase-3. The two divergent pathways of apoptosis converge on the common downstream effector, caspase-3. Pozdzik et al. [41] mentioned that progressive tubular atrophy was related to induction of apoptosis secondary to caspase-3 activation and defective regeneration of tubular epithelial cells. Kaushal et al. [52] the extent of cell injury caused by a toxic agent depend on the balance between activation of caspases triggered by a toxic agent and on the induction of survival signals capable of blocking the activation of caspases. It was stated that the anti-apoptotic effects of EA are due to its inhibition of ROS generation, which, in turn, represses the accumulation of intracellular calcium, stabilizes the mitochondrial membrane and prevents the release of cytochrome $c$ which required for the activation of caspase-3 [53].

In the present work, biochemical results revealed a significant increase in the levels of blood BUN, SC and UA in TCS treated group in comparison with the control group. On the other hand, TCS-EA showed significant decrease in their blood level in comparison with the group TCS treated group. Our results are similar to those of Tootian et al. [33] who found that increases of BUN, SC and UA metabolites following phenol administration are indicators of the biochemical damage to the kidney. In TCS-EA treated group the finding is consistent with Chao et al. [54] who found that dose dependently intake of EA reduced plasma BUN and elevated SC clearance. AL-kharusi et al. [18] mentioned that the antioxidant EA has a protective effect against oxidative stress. Ateşşahin et al. [12] postulated that alterations in glomerular function may be secondary to ROS which induced mesengial cell contraction, altering the filtration surface area and modifying the ultra filtration coefficient factors that decrease the glomerular filtration rate and elevation of BUN and SC.

\section{Conclusion}

In conclusion, TCS leads to alterations in the histological structure and functions of renal cortex of albino rats. EA supplementation protect from these changes and regulating the apoptotic process. So, ellagic can be used as a protective agent against TCS toxicity. Further investigations, as ROS detection in tissue by ROS assay and vitro experiments, are needed to explore the exact mechanisms and the pathogenesis of TCS toxicity.

\section{References}

1. Newton AP, Cadena SM, Rocha ME, Carnieri EG, Martinelli de Oliveira MB (2005) Effect of triclosan (TRN) on energy-linked functions of rat liver mitochondria. Toxicol Lett 160: 49-59.

2. Cooney CM (2010) Triclosan comes under scrutiny. Environ Health Perspect 118: A242.

3. Fang JL, Stingley RL, Beland FA, Harrouk W, Lumpkins DL, et al. (2010) Occurrence, efficacy, metabolism, and toxicity of triclosan. J Environ Sci Health C Environ Carcinog Ecotoxicol Rev 28: 147-171.

4. Canosa P, Rodríguez I, Rubí E, Cela R (2007) Determination of parabens and triclosan in indoor dust using matrix solid-phase dispersion and gas chromatography with tandem mass spectrometry. Anal Chem 79: 1675-1681.

5. Hovander LT, Malmberg M, Athanasiadou I, Athanassiadis S, Rahm A, et al (2002) Identification of Hydroxylated PCB Metabolites and Other Phenolic Halogenated Pollutants in Human Blood Plasma. Archives of Environmental Contamination and Toxicology. 42: 105-117.

6. Allmyr M, Adolfsson-Erici M, McLachlan MS, Sandborgh-Englund G (2006) Triclosan in plasma and milk from Swedish nursing mothers and their exposure via personal care products. Sci Total Environ 372: 87-93. 
7. Calafat AM, Ye X, Wong LY, Reidy JA, Needham LL (2008) Urinary concentrations of triclosan in the U.S. population: 2003-2004. Environ Health Perspect 116: 303-307

8. Morrall D, McAvoy D, Schatowitz B, Inauen J, Jacob M, et al. (2004) A field study of triclosan loss rates in river water (Cibolo Creek, TX). Chemosphere 54: 653-660

9. Crinnion WJ (2010) The CDC fourth national report on human exposure to environmental chemicals: what it tells us about our toxic burden and how it assist environmental medicine physicians. Altern Med Rev 15: 101-109.

10. Dann AB, Hontela A (2011) Triclosan: environmental exposure, toxicity and mechanisms of action. J Appl Toxicol 31: 285-311.

11. Gee RH, Charles A, Taylor N, Darbre PD (2008) Oestrogenic and androgenic activity of triclosan in breast cancer cells. J Appl Toxicol 28: 78-91

12. Ateşşahín A, Ceríbaşi AO Yuce A, Bulmus O, Cikim G (2007) Role of ellagic acid against cisplatin-induced nephrotoxicity and oxidative stress in rats. Basic Clin Pharmacol Toxicol 100: 121-126.

13. Devipriya N, Srinivasan M, Sudheer AR, Menon VP (2007) Effect of ellagic acid, a natural polyphenol, on alcohol-induced prooxidant and antioxidant imbalance: a drug dose dependent study. Singapore Med J 48: 311-318.

14. Tasaki M, Umemura T, Maeda M, Ishii Y, Okamura T, et al. (2008) Safety assessment of ellagic acid, a food additive, in a subchronic toxicity study using F344 rats. Food Chem Toxicol 46: 1119-1124.

15. Loro L, Vintermyr OK, Johannessen AC (2005) Apoptosis in normal and diseased oral tissues. Oral Dis 11: 274-287.

16. Harrington HA, Ho KL, Ghosh S, Tung KC (2008) Construction and analysis of a modular model of caspase activation in apoptosis. Theor Biol Med Mode 5. 26 .

17. Zorrilla LM, Gibson EK, Jeffay SC, Crofton KM, Setzer WR, et al. (2009) The effects of triclosan on puberty and thyroid hormones in male Wistar rats. Toxicol Sci 107: 56-64.

18. Al-Kharusi N, Babiker HA, Al-Salam S, Waly MI, Nemmar A, et al. (2013) Ellagic acid protects against cisplatin-induced nephrotoxicity in rats: a dose-dependent study. Eur Rev Med Pharmacol Sci 17: 299-310.

19. Luque A, Shimizu MH, Andrade L, Sanches TR, Seguro AC (2009) Glomerular filtration is reduced by high tidal volume ventilation in an in vivo healthy rat model. Braz J Med Biol Res 42: 1104-1109.

20. Bancroft JD, Gamble M (2002) Theory and practice of histological techniques. (5th edn), Churchill Livingstone London, New York, Tokyo.

21. Ramos-Vara JA, Kiupel M, Baszler T, Bliven L, Brodersen B, et al. (2008) Suggested guidelines for immunohistochemical techniques in veterinary diagnostic laboratories. J Vet Diagn Invest 20: 393-413.

22. Cattoretti G, Pileri S, Parravicini C, Becker MH, Poggi S, et al. (1993) Antigen unmasking on formalin-fixed, paraffin-embedded tissue sections. J Pathol 171 83-98.

23. Hayat MA (2000) Chemical fixation. In: Hayat MA, editor. Principles and techniques of electron microscopy: biological applications. (4th edn), Cambridge University Press. USA

24. Zhang H, Huang $\mathrm{CH}$ (2003) Oxidative transformation of triclosan and chlorophene by manganese oxides. Environ Sci Technol 37: 2421-2430.

25. Latch DE, Packer JL, Arnold WA and McNeill K (2003): Photochemical conversion of TCS to 2,8-dichlorodibenzo-p-dioxin in aqueous solution $\mathrm{J}$. Photochem. Photobiol. 158: 63-66.

26. Lores M, Llompart M, Sanchez-Prado L, Garcia-Jares C, Cela R (2005) Confirmation of the formation of dichlorodibenzo-p-dioxin in the photodegradation of triclosan by photo-SPME. Anal Bioanal Chem 381: 12941298.

27. Lock EA, Reed CJ (2006) Trichloroethylene: mechanisms of renal toxicity and renal cancer and relevance to risk assessment. Toxicol Sci. 91: 313-331.

28. Mathur PP, D'Cruz SC (2011) The effect of environmental contaminants on testicular function. Asian J Androl 13: 585-591.

29. Tipping PG (2008) Are podocytes passive or provocative in proteinuric glomerular pathology? J Am Soc Nephrol 19: 651-653.

30. Binelli A, Cogni D, Parolini M, Riva C, Provini A (2009) In vivo experiments for the evaluation of genotoxic and cytotoxic effects of Triclosan in Zebra musse hemocytes. Aquat Toxicol 91: 238-244.

31. US EPA (2008): Revised 5-Chloro-2-(2,4-dichlorophenoxy)phenol (TCS): Toxicology Chapter for the Reregistration Eligibility Decision (RED) Document.

32. Barlas N, AydoÄŸan M (2009) Histopathologic effects of maternal 4-tertoctylphenol exposure on liver, kidney and spleen of rats at adulthood. Arch Toxicol 83: 341-349.

33. Tootian Z, Louei Monfared A, Fazelipour S, Shybani MT, Rouhollah F, et al. (2012): Biochemical and structural changes of the kidney in mice exposed to phenol. Turk J Med Sci 42: 695-703.

34. U.S Food and Drug Administration (2008): "Nomination Profile: TCS [CAS 3380-34-5] Supporting Information for Toxicological Evaluation by the Nationa Toxicology Program".

35. Thévenod F (2003) Nephrotoxicity and the proximal tubule. Insights from cadmium. Nephron Physiol 93: p87-93.

36. You CW, Park YH, Lee ES, Kim YJ, Shin SM, et al. (2002) Effects of thyroxine on hyperkalemia and renal cortical $\mathrm{Na}+\mathrm{K}+-$ ATPase activity induced by cyclosporin A. J Korean Med Sci 17: 625-632.

37. Thadhani R, Pascual M, Nickeleit V, Tolkoff-Rubin N, Colvin R (1996) Preliminary description of focal segmental glomerulosclerosis in patients with renovascular disease. Lancet 347: 231-233.

38. Zuckerbraun HL, Babich H, May R, Sinensky MC (1998) Triclosan: cytotoxicity, mode of action, and induction of apoptosis in human gingival cells in vitro. Eur J Oral Sci 106: 628-636.

39. Kaneda K, Iwao, J, Sakata N, Takebayashi S (1992) Correlation between Mitochondrial Enlargement in Renal Proximal Tubules and Microalbuminuria in Rats with Early Streptozotocin-induced Diabetes. Pathology International. 42: $855-860$.

40. Efstratiadis G, Divani M, Katsioulis E, Vergoulas G (2009) Renal fibrosis Hippokratia 13: 224-229

41. Pozdzik AA, Salmon IJ, Debelle FD, Decaestecker C, Van den Branden C, et al. (2008) Aristolochic acid induces proximal tubule apoptosis and epithelial to mesenchymal transformation. Kidney Int 73: 595-607.

42. Rateb, Amal Abdel-Hafez, Amel (2013) Effect of Nigella sativa oil on paracetamol-induced renal cortical damage in rats: light and electron microscopic study The Egyptian Journal of Histology. 36: 127-138.

43. Oh GS, Kim HJ, Choi JH, Shen A, Choe SK, et al. (2014) Pharmacologica activation of NQO1 increases NADâ ${ }^{\circ}$ levels and attenuates cisplatin-mediated acute kidney injury in mice. Kidney Int 85: 547-560.

44. Chirino YI, Pedraza-Chaverri J (2009) Role of oxidative and nitrosative stress in cisplatin-induced nephrotoxicity. Exp Toxicol Pathol 61: 223-242.

45. Hassoun EA, Vodhanel, J, Holden B and Abushaban A (2006) The effects of ellagic acid and vitamin $E$ succinate on antioxidant enzymes activities and glutathione levels in different brain regions of rats after subchronic exposure to TCDD. Journal of Toxicology and Environmental Health. 69: 381-393.

46. Han DH, Lee MJ, Kim JH (2006) Antioxidant and apoptosis-inducing activities of ellagic acid. Anticancer Res 26: 3601-3606.

47. Yu YM, Wang ZH, Liu CH, Chen CS (2007) Ellagic acid inhibits IL-1betainduced cell adhesion molecule expression in human umbilical vein endothelial cells. Br J Nutr 97: 692-698.

48. Türk G, Ceribaşı AO, Sahna E, Ateşşahin A. (2011) Lycopene and ellagic acid prevent testicular apoptosis induced by cisplatin. Phytomedicine 18: 356-361.

49. Cao A, Li Q, Yin P, Dong Y, Shi H, et al. (2013) Curcumin induces apoptosis in human gastric carcinoma AGS cells and colon carcinoma HT-29 cells through mitochondrial dysfunction and endoplasmic reticulum stress Apoptosis : an international journal on programmed cell death. 18: 1391-1402.

50. Youle RJ, Strasser A (2008) The BCL-2 protein family: opposing activities that mediate cell death. Nat Rev Mol Cell Biol 9: 47-59.

51. Kuhla A, Eipel C, Siebert N, Abshagen K, Menger MD, et al. (2008) Hepatocellular apoptosis is mediated by TNFalpha-dependent Fas/FasLigand cytotoxicity in a murine model of acute liver failure. Apoptosis 13: 1427-1438.

52. Kaushal GP, Kaushal V, Hong X, Shah SV (2001) Role and regulation of activation of caspases in cisplatin-induced injury to renal tubular epithelial cells. Kidney Int 60: 1726-1736. 
Citation: Hassan ZA, Abd El-Haleem MR, Mansour GN (2014) Effect of Triclosan on the Renal Cortex of Adult Male Albino Rats and the Possible Protective Role of Ellagic Acid: Histological and Biochemical Study. J Cytol Histol 5: 285. doi:10.4172/2157-7099.1000285

Page 9 of 9

53. Ou HC, Lee WJ, Lee SD, Huang CY, Chiu TH, et al. (2010) Ellagic acid protects endothelial cells from oxidized low-density lipoprotein-induced apoptosis by modulating the PI3K/Akt/eNOS pathway. Toxicol Appl Pharmacol 248: 134-143.
54. Chao CY, Mong MC, Chan KC, Yin MC (2010) Anti-glycative and antiinflammatory effects of caffeic acid and ellagic acid in kidney of diabetic mice. Mol Nutr Food Res 54: 388-395. 